Abstracta Iranica

Revue bibliographique pour le domaine irano-aryen

Volume 22 | 2001

Comptes rendus des publications de 1999

\title{
« Farhangestān va vāže-sāzī ». Našr-e Dāneš, 16, 4 (1378/1999), pp. 10-20.
}

\section{Charles-Henri de Fouchécour}

\section{(2) OpenEdition}

1 Journals

Édition électronique

URL : http://journals.openedition.org/abstractairanica/36957

DOI : 10.4000/abstractairanica.36957

ISSN : 1961-960X

\section{Éditeur :}

CNRS (UMR 7528 Mondes iraniens et indiens), Éditions de l'IFRI

\section{Édition imprimée}

Date de publication : 15 mai 2001

ISSN : 0240-8910

\section{Référence électronique}

Charles-Henri de Fouchécour, « «Farhangestān va vāže-sāzī ». Našr-e Dāneš, 16, 4 (1378/1999), pp. 10-20. », Abstracta Iranica [En ligne], Volume 22 | 2001, document 441, mis en ligne le 17 février 2010, consulté le 13 octobre 2020. URL : http://journals.openedition.org/abstractairanica/36957 ; DOI : https://doi.org/10.4000/abstractairanica.36957

Ce document a été généré automatiquement le 13 octobre 2020.

Tous droits réservés 


\title{
« Farhangestān va vāže-sāzī ». Našr- e Dāneš, 16, 4 (1378/1999), pp. 10-20.
}

\author{
Charles-Henri de Fouchécour
}

Un article qui devra retenir l'attention. Il décrit les règles que devrait se donner l'Académie de la langue et de la culture persanes, et propose un premier résultat. Ces règles permettent de situer le rôle primordial de l'Académie dans ces deux domaines. Celui d'abord de la langue : coordonner les entreprises en cours, orienter les recherches et les enquêtes, juger et établir un vocabulaire persan en évolution, selon les besoins de la société contemporaine. Et celui de la culture, principalement en encourageant l'édition critique des textes. Aux pp.12-20, l'auteur critique les principaux défauts et incohérences constatés dans l'édition du premier fascicule de l'Académie (mordād 1376/1997), où était donnée la correspondance entre mots étrangers et mots nouveaux persans, au nombre de 221/222. Il donne au long des pages une liste de plus de 700 mots en bon persan donnée pour se substituer aux mots fréquents empruntés à l'anglais ou au français. Plus une notion est technique, plus elle est destinée à se transformer, mais aussi : comment renommer en bon persan un objet reconnu uniquement sous sa dénomination étrangère?

\section{INDEX}

Thèmes : 11.1.0. Généralités 


\section{AUTEURS}

\section{CHARLES-HENRI DE FOUCHÉCOUR}

Sorbonne Nouvelle - Paris III 